\title{
A INFLUÊNCIA DAS CORES NO GANHO TÉRMICO DE SUPERFÍCIES CERÂMICAS
}

Rafael Ponce de Leon Amorim (IFPB, Brasil) rafael.ponce@ifpb.edu.br José Rodrigo Viana Monteiro (IFPE, Brasil) rodrigo.viana@afogados.ifpe.edu.br

Resumo: Em regiões de clima quente e úmido, com elevados valores de temperatura e umidade e altos níveis de radiação solar, recomenda-se o emprego de materiais leves, de superfícies com baixa absortância e, principalmente, o sombreamento das superfícies externas, além da permeabilidade das edificações ao vento. Contudo, observa-se nos novos edifícios, o emprego de materiais com alta inércia térmica e alta absortância, acompanhadas pela redução da vegetação e o adensamento inadequado das áreas construídas, características opostas às recomendações bioclimáticas de projeto. O presente artigo teve início com o desenvolvimento de um projeto de pesquisa PIBIC-EM, que teve por objetivo investigar a influência das cores de revestimentos cerâmicos no ganho térmico do edifício através de registros realizados por termômetro infravermeIho e câmera termográfica, demonstrando a necessidade da observação criteriosa da especificação de tal característica no processo de concepção de projeto, e sua consequente contribuição no conforto térmico dos usuários e na eficiência energética do edifício.

Palavras-chave: Cores. Temperatura superficial. Termografia.

\begin{abstract}
In warm and humid climates, with high values of temperature and humidity, and high levels of solar radiation, the use of lightweight materials and low absorptance is recommended and, especially, shading of external surfaces as well as the wind permeability of buildings. However, in new buildings, the use of materials with high thermal inertia and high absortance is observed, accompanied by a reduction in vegetation and inappropriate densification of the built areas, features opposed to bioclimatic design recommendations. This article began with the development of a research project PIBIC-EM, which aimed to investigate the influence of colors of ceramic tiles on the heat gain of buildings through records held by an infrared thermometer and thermal imagery, demonstrating the need for careful observation of the specification of such feature in the process of project design, and its consequent contribution to the users' thermal comfort and energy efficiency of the building.
\end{abstract}

Keywords: Colors. Surface temperature. Thermography. 


\section{Introdução}

O processo de projeto consiste em diversas etapas de análise que se desenvolvem de acordo com a compreensão das necessidades envolvidas, sejam elas funcionais, estéticas, climáticas, econômicas, culturais e tecnológicas, assim como, as suas interações.

Neste sentido, o projetista deve ter domínio sobre todas as interfaces de projeto, a fim de alcançar um bom resultado. Dentre as características citadas, a análise climática é fundamental para a obtenção do conforto ambiental e da eficiência energética nas edificações, ao observar os elementos e fatores climáticos locais, sintetizando as necessidades de interação entre o edifício e o ambiente no qual está inserido.

De acordo com Olgyay (1989) a finalidade da edificação está em cumprir satisfatoriamente as necessidades fisiológicas humanas, estabelecendo o equilíbrio dos principais elementos que afetam o conforto térmico: radiação solar, ventilação, temperatura e umidade do ar. Dessa forma, a envoltória do edifício exerce papel fundamental em seu desempenho térmico, pois é através dela que ocorre a interação entre o ambiente interno e o externo, funcionando como um filtro que permite a passagem dos elementos que são desejáveis e bloqueando os indesejáveis.

A envoltória é formada pelo conjunto de planos que separam o ambiente interno do ambiente externo, tais como paredes, empenas, cobertura, aberturas, e outros elementos, composto de elementos opacos - que absorvem e refletem a radiação - e elementos transparentes e translúcidos - que permitem a transmissão direta ou difusa de parte da radiação solar (RTQ-R, 2010).

O impacto da carga térmica dos edifícios resultante da incidência de radiação solar depende em grande parte de uma propriedade denominada absortância, que é definida como a razão entre a energia solar absorvida por uma superfície e a energia total incidente sobre a mesma. E, também, da transmiância térmica do sistema construtivo empregado. $\mathrm{O}$ balanço de energia de uma edificação depende da radiação solar incidente sobre as superfícies externas, dessa forma, a absortância das superfícies externas determina o efeito que a radiação solar terá sobre a edificação, porém este desempenho, como controlador das temperaturas internas, é variável (GIVONI, 1998).

Nas regiões de clima quente a radiação solar incidente na envoltória é a principal responsável pelo aumento da temperatura do ar do edifício podendo provocar desconforto térmico aos seus usuários de acordo com as características do edifício. Porém, este efeito pode ser reduzido com o uso de pintura ou revestimento de cor clara. Havendo também outras possibilidades de intervenção, tais como, o uso do sombreamento por meio de vegetação ou dispositivos de proteção solar nas superfícies externas, ou o emprego de materiais isolantes na envoltória, uso de massa térmica para amortecer internamente a variação da temperatura, além do uso da ventilação.

Em um edifício existente, a maior parte das alternativas citadas para adequação climática 
requerem altos investimentos, desde a contratação de um profissional responsável pelo projeto aos custos das soluções, além do tempo requerido para a intervenção. Sendo assim, a adoção de cores claras nas fachadas pode ser vista como uma solução simples, eficiente e de baixo custo, dependendo das características arquitetônicas do edifício.

Neste sentido, esta pesquisa avaliou o comportamento térmico superficial de pastilhas cerâmicas de diferentes cores, comumente utilizadas em revestimento de fachadas de edifícios multifamiliares verticais, sob a incidência direta da insolação em uma cidade de clima quente e úmido, João Pessoa/PB. Isso visando demonstrar a importância da escolha criteriosa das cores das superfícies externas da edificação em função da absortância solar.

\section{Revisão literária}

Nas áreas urbanas diversas construções absorvem e retém mais calor do sol do que materiais naturais, os materiais de construção em sua maioria são impermeáveis e estanques. E não apresentam umidade disponível para dissipar o calor do sol, e os materiais de revestimento de cor escura, em edifícios e pavimentos, também apresentam maior capacidade de absorver e reter o calor quando expostos a radiação direta. Além dos materiais construtivos o fluxo de pessoas e veículos incrementa o acúmulo de calor no ambiente urbano. A complexidade de se analisar esta diversidade de elementos carece de estudos.

$\mathrm{O}$ homem influencia as condições térmicas do meio ambiente com diversas ações e ativida- des, provocando transformações na ocupação e modelação do espaço urbano, recriando condições ao ambiente de forma que o meio se adapte às suas intenções. A intensificação do adensamento da área construída no espaço urbano traz consequências negativas, como a retirada da vegetação e cobertura natural do solo para o incremento de novos espaços pavimentados e construções, incrementando diferenciações no tempo de absorção de energia solar nas superfícies que constituem as áreas urbanas.

Conforme Monteiro e Mendonça (2002) a maior capacidade de estocagem de calor em função das propriedades dos materiais de construção da cidade; a redução do fluxo de calor latente e o aumento do calor sensível em função da reduzida superfície líquida e de áreas verdes na área urbana, resultando em diminuição da umidade e menor evaporação; a redução do sky view factor por elementos urbanos edifícios - resultando em menores perdas de radiação de ondas longas nas ruas e canyons urbanos contribuindo para o aumento de ocorrências de inundações urbanas provocadas, em parte, pela impermeabilização do solo e de episódios de poluição atmosférica, uma vez que a geometria dos prédios produz o aprisionamento do ar e uma superfície de grande aspereza.

A radiação solar é responsável por uma parcela significativa da carga térmica nos edifícios, ao ser absorvida pelas superfícies exteriores origina um armazenamento de calor que, por convecção e condução, pode aquecer e causar o desconforto no espaço urbano. O albedo corresponde a quantidade de radiação solar refle- 
tida por um corpo ou uma superfície, variando de 0 a 1 , trata-se da razão entre a quantidade de radiação refletida pela quantidade de radiação recebida, fornecendo a informação sobre a capacidade de uma superfície de refletir energia solar incidente sobre a superfície terrestre. As superfícies com pouca absorção, como a vegetação e gramado tem albedo em torno de 0,25 que é abaixo da média da terra de 0,31 , já o asfalto tem albedo de 0,04, apresentando reflexão do calor irradiado muito baixo (OKE, 1987).

Nas regiões de clima quente o efeito da radiação solar que incide nas paredes pode aumentar a temperatura interna do ar provocando um desconforto térmico no ambiente, este efeito pode ser reduzido com o uso da pintura ou revestimento de cor clara. A cor é uma percepção visual provocada pela ação de um feixe de fótons sobre as células da retina que transmitem ao nervo óptico impressões para o sistema nervoso. A cor de um material é determinada pelas frequências de onda que se refletem. Um objeto terá determinada cor se não absorver justamente os raios correspondentes à frequência daquela cor.

Segundo Dornelles (2008) utilizar a percepção visual, resulta em valores médios de absortâncias e refletâncias em superfícies, que nem sempre correspondem aos valores reais, assim nem sempre uma cor considerada mais clara que outra apresentará baixos valores de absortância ou refletância.

A investigação sobre o efeito da cor da envoltória, com o uso de cores mais claras (baixa absortância) na superfície demonstra resultados significativos de redução da temperatura interna na edificação (CHENG, 2005), mas apenas a escolha da cor não pode reduzir a temperatura interna ao nível de conforto térmico humano.

A aplicação da cor no projeto de construção denota diferentes circunstâncias. A escolha e seleção de cores utilizadas são subjetivas e simbólicas, decididas por um estilo arquitetônico e senso visual, que às vezes contrapõe-se aos requisitos de adequação ao conforto térmico (WU, 2009). Entretanto o uso intensivo de cores claras, de baixa absortância, principalmente na envoltória da edificação e no espaço urbano, pode causar a sensação de desconforto visual, como ofuscamento e alta reflexão nos usuários e em edificações vizinhas (SYNNEFA, 2011).

A termografia trata-se da técnica de medição sem contato da temperatura de uma superfície, através de uma imagem gerada pela radiação térmica na faixa do infravermelho, com comprimento de onda de 0,75 a $10 \mu \mathrm{m}$ emitida pela superfície, transforma a emissão do objeto em imagem visível sendo detectada pela câmera três componentes de radiação dos objetos, a emissão, a transmissão e a reflexão (OCAÑA; GUERRERO; REQUENA, 2004). A termografia infravermelha vem sendo empregada também no diagnostico de ganhos e perdas de calor nas edificações e no meio urbano, dentre as principais condições que influenciam a medição está o valor de emissividade, a condição ambiental, o tipo de cor da superfície e a refletividade da superfície (BARREIRA; FREITAS, 2007). 
A câmera infravermelha de termografia é um dispositivo que detecta a energia infravermelha (calor), através de um sinal eletrônico produzindo imagens e executando cálculos de temperatura. Portanto a câmera infravermelha não mede a temperatura, mas sim a calcula. Isto é feito com base na radiação emitida por corpos e informações fornecidas ao equipamento visando compensar certos pontos que podem afetar os valores, em especial a emissividade. A câmera capta a radiação infravermelha emitida pela superfície convertendo em sinais elétricos, criando uma imagem térmica com gradiente de temperatura superfície (BARREIRA; FREITAS, 2007).

Conforme estudos realizados por Marinoski (2010), algumas informações do ambiente e da superfície a ser analisada devem estabelecer alguns dados de entrada, que são definidos pelo operador, como a emissividade.

A emissão da radiação eletromagnética depende de uma propriedade chamada emissividade $(\varepsilon)$, que apresenta valores na faixa de 0 à 1 , superfícies com baixos valores de emissividade, próximos a 0 são altamente refletores, enquanto valores próximos a 1 são perfeitos emissores, propriedade esta que fornece a capacidade de emissão de energia de uma superfície em relação a um corpo negro (AVDELIDIS; MOROPOULOU, 2003). A maioria dos materiais de construção apresentam valores de emissividade de 0,90 a 0,95 , o que torna possível obter corretos valores de temperatura (OCAÑA; GUERREIRO; REQUENA, 2004).

Na realização dos testes termográficos algumas recomendações são importantes, deve-se evitar a exposição da direção da lente diretamente à radiação solar. A velocidade do vento deve ser menor que $1 \mathrm{~m} / \mathrm{s}$, a fim de evitar que o processo de convecção causado pela ventilação natural na superfície altere os resultados no momento do registro da imagem. Também, devem-se evitar registros em períodos com fortes chuvas, devido a ausência de diferenças de temperatura superfície e temperatura do ar nestas condições. (ALBATICI; TONELLI, 2010).

Testes realizados com a câmera termográfica apresentaram resultados satisfatórios de interpretação de imagens em horários específicos, como no início da manhã, por volta das 8:00 h, e o período próximo ao final da tarde, entre 15:00 h e 16:00 h. Essa constatação coincide com as recomendações de outros autores, que indicam horários de início e final do dia para medições com a câmera termográfica (OCAÑA; GUERREIRO; REQUENA, 2004).

\section{Metodologia de pesquisa}

A presente pesquisa foi realizada em duas etapas, na primeira analisou-se o comportamento térmico de pastilhas cerâmicas isoladas, $10 \mathrm{x}$ $10 \mathrm{~cm}$, de seis diferentes cores (branca, preta, azul, verde, azul e amarela). Inicialmente à sombra e, posteriormente, expostas à radiação solar direta, sendo as medições realizadas em intervalos de 5 minutos, após seis medições, as pastilhas foram levadas novamente à sombra, onde foram realizadas duas novas medições.

$\mathrm{Na}$ segunda etapa, realizou-se um passeio pela orla da cidade, identificando-se as cores dos revestimentos mais utilizados, assim como, a relação com a orientação dos edifícios, além do 
registro fotográfico com a câmera termográfica e uma câmera comum.

Os registros das temperaturas superficiais foram realizados com auxílio de um termômetro infravermelho, marca ICEL, modelo TD-950 e uma câmera termográfica, marca FLIR, modelo I5.

\section{Resultados}

No mês de dezembro foi realizado o primeiro experimento com seis peças cerâmicas de diferentes cores: branca, preta, azul, verde, azul e amarela. A primeira medição foi efetuada com as peças à sombra, sem incidência da radiação direta, e, em seguida, as peças foram expostas ao sol, sendo realizadas seis medições em intervalos de 5 minutos. Por fim, os dois últimos registros foram realizados à sombra com o intuito de identificar o resfriamento das peças. Observa-se inicialmente, no Gráfico 1, que as peças registraram o mesmo valor de temperatura, confirmando a eficiência da estratégia de sombreamento para o desempenho térmico das superfícies, pois com predominância de radiações de onda longa à sombra, a absortância das diferentes superfícies apresentam características semelhantes.

Em seguida, com exposição ao sol, as temperaturas superficiais se elevaram e se distanciaram umas das outras, alcançando o valor máximo às $11: 25$, com 15 minutos de exposição a radiação solar direta, registrando $39^{\circ} \mathrm{C}$ na superfície branca e $64^{\circ} \mathrm{C}$ na superfície preta, alcançando uma amplitude de $25^{\circ} \mathrm{C}$.

Em seguida, com alteração nas condições de céu, devido à presença de nuvens e obstrução do sol, as superfícies resfriaram e mantiveram um comportamento mais constante, entre $11 \mathrm{~h} 30 \mathrm{~min}$ e $11 \mathrm{~h} 40 \mathrm{~min}$. Observa-se que as superfícies com cores mais claras, branco e amarelo, apresentaram valores de temperatura inferiores ao conjunto de cores intermediárias, verde, vermelho e azul, enquanto a mais escura, cor preta, apresentou valores superiores.

Por fim, à sombra, as peças resfriaram rapidamente, devido à ausência da radiação direta, e também à sua pouca massa térmica, por tratarse de peças isoladas do sistema construtivo, além de alta emissividade, comum aos materiais de construção, auxiliando na perda de calor por radiação.

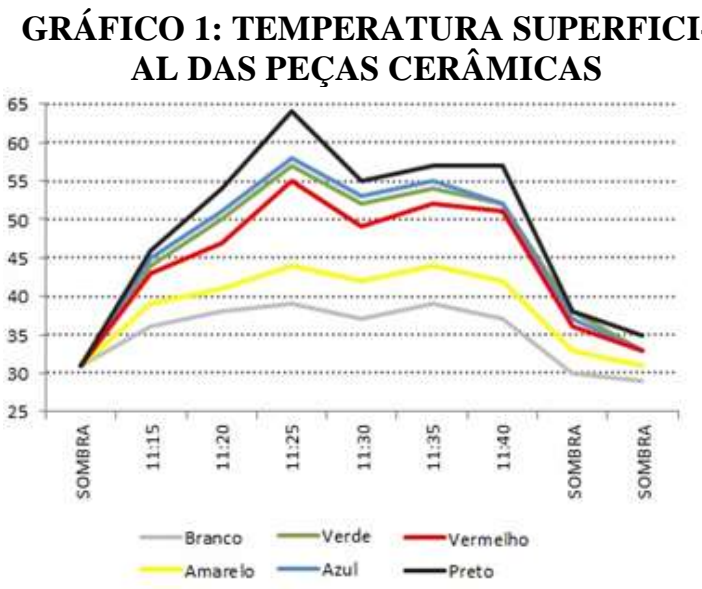

Fonte: Elaborado pelos autores

No dia 15 de janeiro, foi realizado o segundo experimento às $15 \mathrm{~h}$, com o uso de uma câmera termográfica. Observa-se na Figura 1, o conjunto de pastilhas cerâmicas, e, na Figura 2, a sua respectiva imagem termográfica. Onde podem ser verificadas as temperaturas superficiais após a exposição à radiação solar direta em um intervalo de aproximadamente $10 \mathrm{mi}-$ nutos.

As cerâmicas apresentaram comportamento 


\section{ReLAInEF}

semelhante ao observado nas coletas de dados anteriores, porém com menor amplitude térmica devido ao horário com menor radiação solar. A cerâmica de cor preta registrou temperatura de $44,2^{\circ} \mathrm{C}$, enquanto a de cor branca, $36,3^{\circ} \mathrm{C}$, variação de aproximadamente $8^{\circ} \mathrm{C}$.

\section{FIGURA 1: CONJUNTO DE PEÇAS CERÂ- MICAS DE DIFERENTES CORES EXPOSTAS À RADIAÇÃO SOLAR DIRETA}

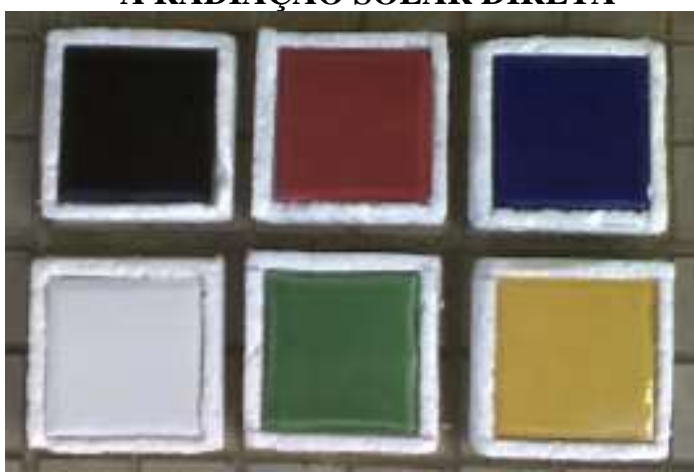

Fonte: Elaborado pelos autores

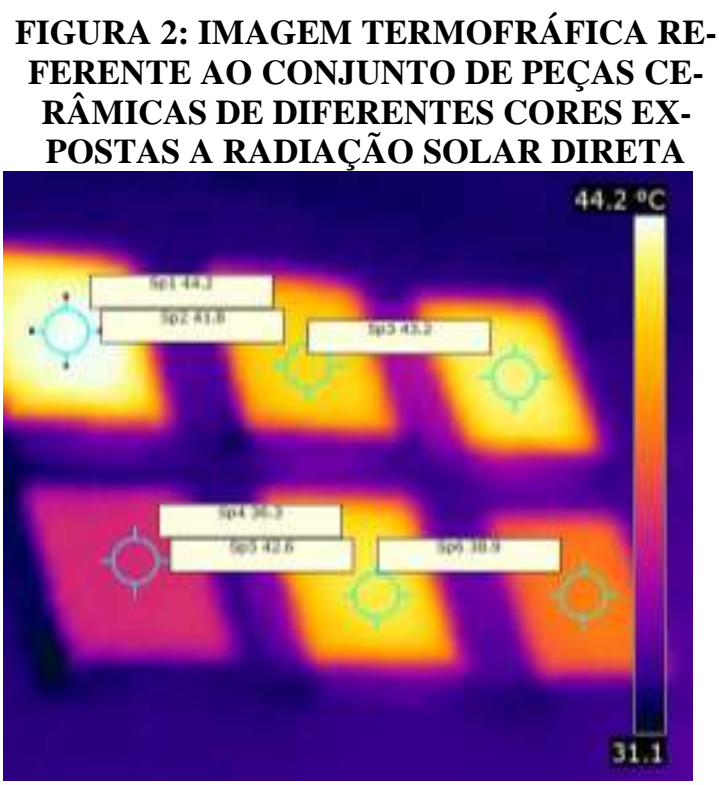

Fonte: Elaborado pelos autores

A segunda etapa da pesquisa consistiu na observação de edificações verticais multifamiliares, localizados no bairro Cabo Branco na cidade de João Pessoa/ PB. Onde foram analisadas as relações entre as diferentes cores dos revestimentos cerâmicos das envoltórias. As- sim como, a orientação de cada fachada e as temperaturas superficiais resultantes da interação dessas características com a radiação solar. Observou-se em geral, a predominância de cores claras, porém o emprego de cores escuras, especificadas apenas por razões estéticas sem a devida preocupação com a potencialização do ganho térmico é notória.

Na Figura 3, observa-se a fachada leste de um edifício residencial, percebe-se a grande variação de temperatura entre as superfícies branca e marrom, que alcançam amplitude de aproximadamente $5^{\circ} \mathrm{C}$, respectivamente, $25,8^{\circ} \mathrm{C}$ e $31,1^{\circ} \mathrm{C}$, mesmo após não receberem mais radiação direta devido ao horário, 16:30, o que leva a confirmação do atuação da inércia térmica, e da radiação indireta e difusa no ganho de calor do edifício.

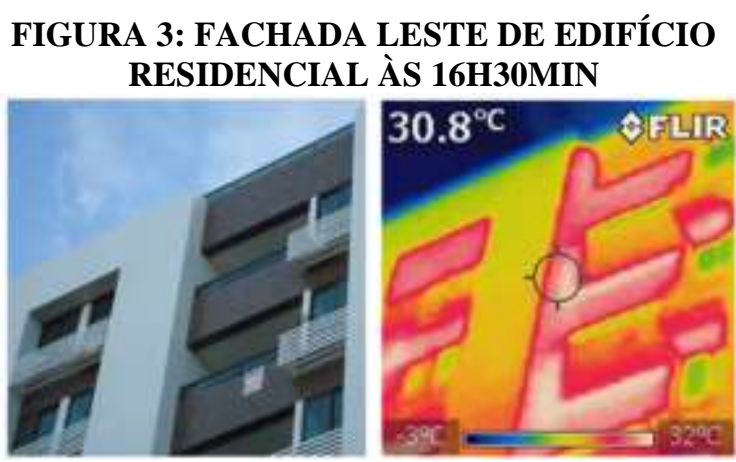

Fonte: Elaborado pelos autores

As Figuras 4 e 5 referem-se a duas fachadas voltadas para o norte e que por tratar-se do período de verão não recebiam radiação direta. O edifício da Figura 4 registrou diferença de temperatura superficial em torno de $5^{\circ} \mathrm{C}$ entre as cores branca e azul, $31,6^{\circ} \mathrm{C}$ e $34,7^{\circ} \mathrm{C}$, enquanto o edifício da Figura 5, com superfícies nas cores branca, amarela, verde e preta, registrou amplitude máxima superior a $7^{\circ} \mathrm{C}$, respectivamente, $26,1^{\circ} \mathrm{C}$ e $33,5^{\circ} \mathrm{C}$, cores branca e 


\section{ReLAInEF}

preta.

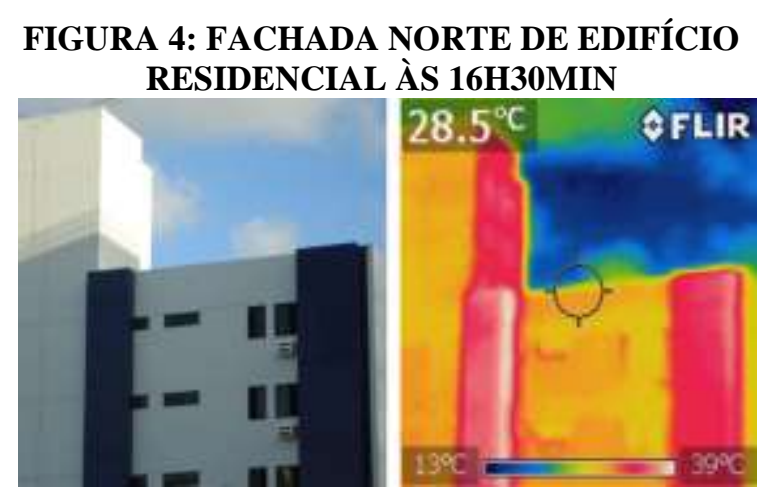

Fonte: Elaborado pelos autores

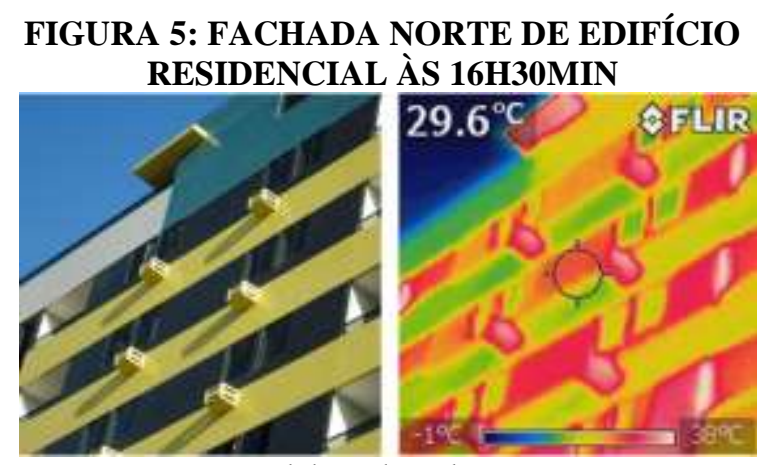

Fonte: Elaborado pelos autores

Nas Figuras 6 e 7, é interessante observar a diferença de temperatura entre as fachadas que recebem radiação direta e as que recebem apenas radiação difusa e indireta. No edifício da Figura 6 observou-se uma diferença de $11^{\circ} \mathrm{C}$ entre a faixa de cor verde escura na fachada norte e a sua continuidade na fachada oeste, respectivamente, $31,3^{\circ} \mathrm{C}$ e $42,3^{\circ} \mathrm{C}$.

\section{FIGURA 6: FACHADA NORTE E OESTE DE} EDIFÍCIO RESIDENCIAL ÀS 16:30

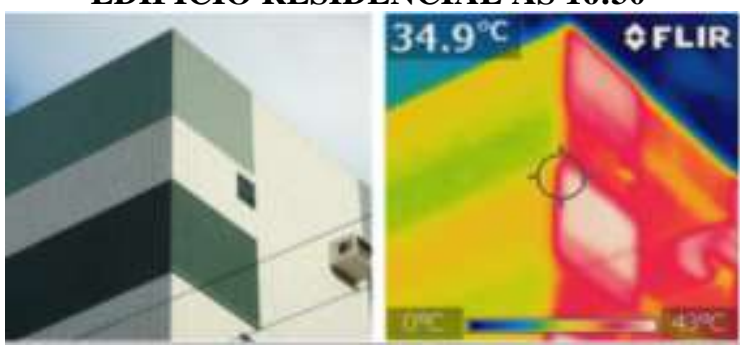

Fonte: Elaborado pelos autores

$\mathrm{Na}$ Figura 7, a diferença alcança $10^{\circ} \mathrm{C}$ entre as superfícies marrons das fachadas norte e oeste, respectivamente, $46,3^{\circ} \mathrm{C}$ e $36,3^{\circ} \mathrm{C}$, e amplitude de $7,5^{\circ} \mathrm{C}$ entre as superfícies brancas, $31,5^{\circ} \mathrm{C}$ e $39^{\circ} \mathrm{C}$.

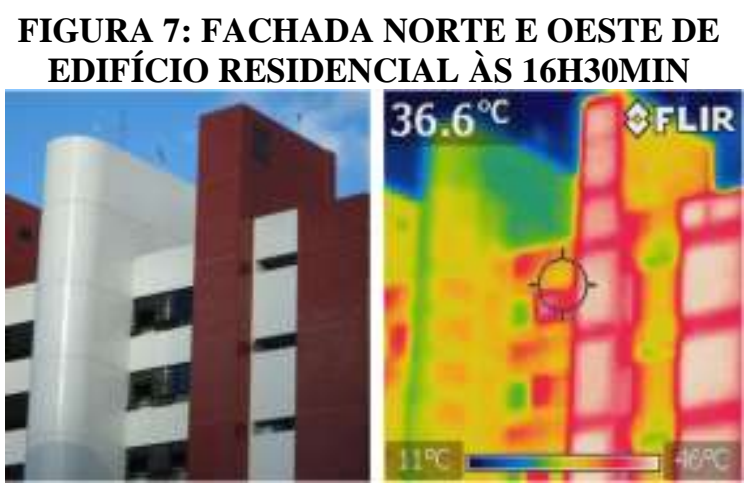

Fonte: Elaborado pelos autores

Por fim, na Figura 8 observou-se a maior diferença registrada nesta pesquisa, amplitude de $12,7^{\circ} \mathrm{C}$, respectivamente, $39^{\circ} \mathrm{C}$ e $51,7^{\circ} \mathrm{C}$ entre as cores branca, azul e preta. Resultando em um excessivo ganho térmico da envoltória, que dependendo de sua resistência térmica poderá contribuir fortemente para o desconforto ou para o aumento do consumo energético com refrigeração dos ambientes internos ao edifício, a fim de propiciar conforto térmico aos seus ocupantes.

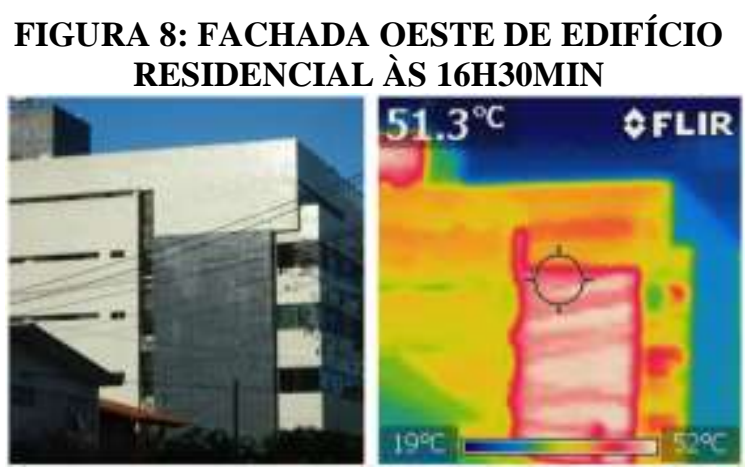

Fonte: Elaborado pelos autores

\section{Conclusões}

Os revestimentos cerâmicos são amplamente utilizados no setor da construção civil, sua principal função é a de proteger a alvenaria, e, 
neste sentido, estes revestimentos apresentam diversas vantagens: beleza, durabilidade, facilidade de limpeza, material antialérgico e antiinflamável, dentre outras.

Quanto às propriedades térmicas da envoltória, diversas características irão condicionar o comportamento do edifício, sendo as mais relevantes a capacidade de absorção da superfície e a resistência térmica do sistema construtivo utilizado.

Neste sentido, observou-se a importância do emprego de cores claras em fachadas que são expostas diretamente a radiação solar. Percebese que, em um primeiro momento, a indicação da absortância deve ser realizada através da observação da saturação, entre cores claras, médias e escuras, como indicado na NBR 15220 e não, como sugerido em algumas bibliografias, de acordo com o seu matiz.

Outros estudos devem ser realizados para avaliar o comportamento térmico de pastilhas cerâmicas, ao analisar o comportamento individual em cada faixa do espectro solar, composto por radiações ultravioleta, luz visível e infravermelha. Sem esquecer também da rugosidade da superfície que é um importante elemento a ser considerado, por ter influência direta no índice de absorção.

A presente pesquisa avaliou o comportamento térmico de seis diferentes cores de pastilhas cerâmicas isoladas, além de diversos edifícios construídos. Observou-se que apesar da absortância ser um conceito amplamente conhecido e debatido no meio acadêmico, no ambiente construído, pouco tem se dado à devida atenção quando da escolha dos revestimentos externos dos edifícios.

\section{Referências}

ALBATICI, R.; TONELLI, A.M. Infrared Thernovision Technique for the Assessment of Thermal Transmittance Value of Opaque Building Elements on Site. Energy and Buildings, v. 42, p. 2177-2183, 2010.

AVDELIDIS, N.P.; MOROPOULOU, A. Emissivity Considerations in Building Thermography. Energy and Buildings, v.35, p.663-667, 2003.

BARREIRA, E.; FREITAS, V.P. Evaluation of Buildings Materials Using Infrared Thermography. Construction and Building Materials, v. 21, p. 218-224, 2007.

CHENG, V.; NG. E.; GIVONI, B. Effect of envelope colour and thermal mass on indoor temperatures in hot humid climate. Solar Energy, v. 78, p. 528-534, 2005.

DORNELlES, K. A. Absortância solar de superfícies opacas: método de determinação e base de dados para tintas látex acrílica e PVA. 2008. 152f. Tese (Doutorado) Programa de Pós-Graduação da Faculdade de Engenharia Civil, Arquitetura e Urbanismo da Universidade Estadual de Campinas.2008.

GIVONI, B. Effectiveness of mass and night ventilation in lowering the indoor daytime temperatures. Part I: 1993 experimental periods. Energy and Buildings, v. 28, p. 25-32, 1998.

MARINOSKI, D. L.; SOUZA, G. T. DE; SANGOI, J. M.; LAMBERTS, R. Utilização de Imagens em Infravermelho para Análise Térmica de Componentes Construtivos. $13^{\circ}$ Encontro Nacional de Tecnologia do Ambiente Construído, Canelas/Brasil. ENTAC 2010.

MENDONÇA, F.; MONTEIRO, C.A.F. Clima Urbano. São Paulo: Contexto, 2002.

OCAÑA, S.M.; GUERRERO, I.C.; REQUENA, I.G. Thermographic survey of two rural buildings in Spain. Energy and Buildings, v. 36, p.515-523, 2004.

OKE, T R; A CLUEUG, H. Urban heat storage derived as energy balance residuals. New York: Boundary- Layer Meteorology, 1987. 
Olgyay, V.; Olgyay, A. Design with climate: bioclimatic approach to architectural regionalism. Princeton University Press, $5^{\mathrm{a}}$ ed. 1989.

INMETRO. Regulamento Técnico do Nível de Eficiência Energética de Edifícios Residenciais. Rio de Janeiro: INMETRO, 2010.

SYNNEFA, A.; KARLESSI, T.; GAITANI ,N.I; SANTAMOURIS, M.; ASSIMAKOPOULOS,D.N; PAPAKATSIKAS, C. Experimental testing of cool colored thin layer asphalt an destimation of its potential to improve the urban microclimate. Building and Environment, v. 46, p. 38-44, 2011.

WU, Y., LI, D., JIN, R., LIU, L., BAI, J.; FENG, J. Thermographyc Method for Evaluation of Thermal Influence of Exterior Surface Colour of Buildings. Proceeding of SPIE, v. 7160, p. 7160-7167, 2009. 